Systematic Review

\title{
Support Factors of Self Foot Care for Diabetes Mellitus Patients
}

\section{Rohmatul Faizah, Gabriel Wanda Sinawang, Andrik Hermanto, and Mohamad Roni Alfatih}

Faculty of Nursing, Universitas Airlangga, Surabaya, Indonesia

\begin{abstract}
Introduction: Diabetes mellitus is a chronic disease of the endocrine system that has numerous complications such as diabetic foot ulcers. Amputation is the last frontier for the treatment of diabetic foot ulcers but they can be prevented through proper self-foot-care behavior. The aim of this study was to explain the support factors of self foot care for diabetes mellitus patients.

Methods: The methods used were self-foot-care identification in the literature, with the relevant literature identification based on the topics and titles obtained from Scopus, ScienceDirect and ProQuest. This was as well as analysis of the results from examining the various behaviors that support self-foot-care behavior in the literature. The references included was the research conducted from 2013 - 2019 as follows: 2 descriptive correlation studies, 3 descriptive studies, 2 prospective studies, 1 prospective cohort study, 1 pre-experimental study, 3 quasi-experimental studies, 1 case study and 3 cross-sectional studies.

Results: All of the journals included discussed foot care behavior. Education programs regarding foot care are a major factor that supports foot care behavior.

Conclusion: All of the journals that were obtained stated that there was a positive influence on the diabetic foot condition where routine foot care behavior was implemented. Self-foot-care behavior also requires other supporting factors to obtain the maximum results.
\end{abstract}

\section{ARTICLE HISTORY}

Received: Dec 26, 2019

Accepted: Dec 31, 2019

\section{KEYWORDS}

self foot care; foot care behavior; diabetic foot; diabetes mellitus

\section{CONTACT}

Rohmatul Faizah

$\triangle$ rohmatul.faizah-

2018@fkp.unair.ac.id

$\equiv$ Faculty of Nursing, Universitas

Airlangga, Surabaya, Indonesia

Cite this as: Faizah, R., Sinawang, G., Alfaqihand, M., \& Hermanto, A. (2019). Support Factors of Self Foot Care for Diabetes Mellitus Patients. Jurnal Ners, 14(3si), 316-320. doi:http://dx.doi.org/10.20473/in.v14i3(si).17167

\section{INTRODUCTION}

Diabetes mellitus is a chronic disease in the endocrine system, which occurs due to the disruption of glucose metabolism in the body. The disorder of glucose metabolism is caused by several factors. Previously, it was known that glucose breakdown in the body requires the insulin hormone and that this hormone is produced by the pancreas gland(Moradi, Alavi, Salimi, Nouhjah, \& Shahvali, 2019).

There is quite a large number of diabetes mellitus patients globally. According to the WHO (2015), there are 415 million adults with diabetes mellitus. The number has increased each year and it is predicted to reach 642 million in 2040. Indonesia ranked 6thin South East Asia for the mortality rate of people with diabetes mellitus. The results from Riskesdas (2018) stated that people with diabetes mellitus in Indonesia have increased by $3.4 \%$ since 2013 [3].
In general, there are 2 major factors causing diabetes mellitus; disorders of the pancreatic organs or a lifestyle disorder. For the pancreatic gland disorders, the problem is that the amount of the insulin hormone is insufficient for the body's requirement to carry out glucose metabolism. For lifestyle disorder, the problem is the excessive amount of glucose in the body, causing it to not be fully metabolized. Diabetes mellitus is a noncommunicable disease. Regardless, this disease still requires appropriate treatment. The treatment given to patients with diabetes mellitus is a life-long treatment, therefore compliance is required to achieve optimal results. The treatment of diabetes mellitus consists of 5 key principles(Cousart \& Handley, 2017).

Uncontrolled diabetes mellitus can lead to complications. One problem that is often found as a complication is diabetic feet. The complication of poorly-treated diabetic feet is amputation. The 
intervention measure used to handle diabetic foot problems is proper foot care. Diabetic feet could be prevented with proper self-foot-care behavior (Al Sayah, Soprovich, Qiu, Edwards, \& Johnson, 2015). The systematic review will discuss appropriate foot care behavior and its supporting factors. The limitation of the self foot care of diabetes mellitus patients at home is that the nurse can't accompany the patient 24 hours around the clock. Therefore the ability to self foot care is needed by the patient and their family. The literature explained that the supporting factors for independent self foot care came from education, the media used to provide health education and health education in accordance with culture.

\section{MATERIALS AND METHODS}

\section{Research Design}

This study used a systematic review by finding out the support factors of self foot care for diabetes mellitus patient. This study explained the results drawn from the research published in journals internationally.

\section{Search Strategy}

This research reviews the support factors of self foot care through the process of electronic database searching which was limited to between 2013 and 2019. The literature was used from Scopus, ScienceDirect and ProQuest. The keywords used in the literature search were self foot care and diabetes mellitus disease.

\section{Inclusion and Exclusion Criteria}

The inclusion criteria of the research in this systematic review were: 1) experimental and nonexperimental studies, 2) there were no limitation regarding age and the amount of participants in the literature collection and 3) the research was conducted from 2013 - 2019. Meanwhile, for the exclusion criteria, it was 1) the research samples or respondents with diabetic foot problems.

\section{Article Search Process}

This research article was obtained from Scopus, Science Direct, and ProQuest. This research found 6.679 articles during search. A detailed process of the mechanism for selecting research can be seen in the table below.

\section{RESULTS}

There were 16 literature studies obtained: 2 descriptive correlation studies, 3 descriptive studies, 2 prospective studies, 1 prospective cohort study, 1 pre-experimental study, 3 quasi experimental studies, 1 case study and 3 cross sectional studies. There were also interventions that were used as comparisons or combinations as described in Table 1. All of the literature taken stated that that there was success concerning the diabetes mellitus patients and

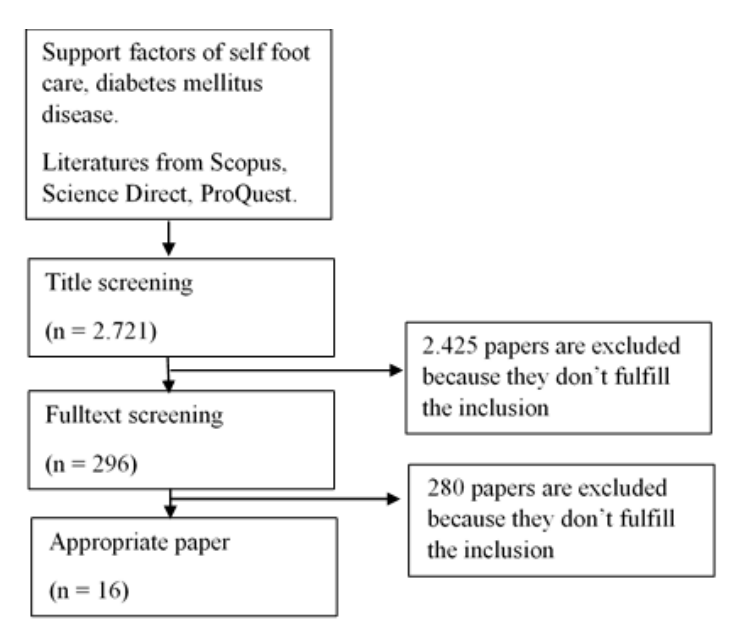

Figure 1. Flowchart of research support factors of self foot care for diabetes mellitus

self foot care as indicated by either the patient or their family. Ten items of literature explained that the main factor of the success of foot care was the health education provided. Health education can be a success with the right education media. Two literature items explained about using electronic media for health education such as a handphone, television and radio. The health education took on the form of a Short Message Service (SMS) or a message post using a social media account. Health education through a social media account resulted in $45,7 \%$ posts being categorized as useful out of 103 posts. The limitation of health education through electronic media is that the patient may not be able to operate a handphone. So, the patients need support from their family. There were 3 items of literature that explained about health education aligned with culture and that self efficacy has an influence on the increase of self foot care. One literature explain that the SDFQ-UMA questionnaire was a valid tool that could be used to evaluate foot care in DM patients.

\section{DISCUSSION}

Good foot care behavior in diabetes mellitus patients is needed. The main factor in the development of diabetic foot care behavior is health education. The health education provided to diabetes mellitus patients can be done using various media.

\section{Health Education}

Health education is defined as efforts starting from the planning stage which eventually aim to affect people on different levels (i.e. individuals, groups or communities). Health education is carried out in the hope that the targets could implement the knowledge that is obtained. Health education addresses health issues ranging from health promotion through to treatment techniques. Health education has important elements, including input, the process itself and output. The input in health education is the targets and the educators, while the process is the 
Table 1. Systematic Review of the Established Studies

\begin{tabular}{ll}
\hline \multicolumn{1}{c}{ Author writer } & \multicolumn{1}{c}{ Result of literature } \\
\&endling and Beadle (Wendling & $\begin{array}{l}\text { There was no significant correlation between the level of self-efficacy and foot care } \\
\text { behavior. However, foot care behavior had significant results with gender, which } \\
\text { was higher in men. }\end{array}$ \\
\hline $\begin{array}{l}\text { Vedhara et al (Vedhara et al., } \\
\text { 2014) }\end{array}$ & $\begin{array}{l}\text { The patient's beliefs in the illness that they experienced, which is a diabetic foot } \\
\text { ulcer, became an important supporting factor in improving foot care behavior. }\end{array}$ \\
\hline $\begin{array}{l}\text { Sharoni et al (Sharoni, Abdul } \\
\text { Rahman, Minhat, Shariff Ghazali, } \\
\text { \& Azman Ong, 2017) }\end{array}$ & $\begin{array}{l}\text { A self efficacy education program could increase the elderly patients' improvement } \\
\text { related to foot care behavior due to the enhancement of acceptance level, } \\
\text { expectations of foot care behavior, foot care knowledge, quality of life, FBG, foot } \\
\text { hygiene and anhydrosis }\end{array}$ \\
\hline Li et al (Li et al., 2014) & $\begin{array}{l}\text { Foot care behavior was dependent on and had a positive correlation with individual } \\
\text { knowledge level. The affecting factors include education, a long diabetes mellitus } \\
\text { diagnosis, periodic examinations and education regarding DM complications }\end{array}$ \\
\hline Navarro-Flores et al (Navarro- & $\begin{array}{l}\text { The SDFQ-UMA questionnaire was a valid tool that could be used to evaluate foot } \\
\text { care in DM patients. }\end{array}$ \\
Flores, Morales-Asencio, &
\end{tabular}

Cervera-Marín, Labajos-

Manzanares, \& Gijon-Nogueron, 2015)

D'Souza et al (D'Souza et al., 2016)

Foot care behavior had a positive correlation with high income, high education, low weight, positive attitude and a high awareness of diabetes as well as its management.

Indrayana et al (Indrayana, Guo, Lin, \& Fang, 2019)

Disease perception, local beliefs such as consequences, personal control, treatment control and coherence had a good contribution when it came to improving patient behavior in relation to foot care.

Adarmouch et al(Adarmouch et There was an increase in foot care after the intervention in the form of health al., 2017) education tailored to the culture was given.

Al Sayah et al (Al Sayah et al., $\quad$ DM patients with diabetic feet need to carry out self-care and monitor their clinical 2015) conditions regularly, so then DM can be controlled.

Moradi et al (Moradi et al., 2019) SMS increased the knowledge and behavior of diabetic foot ulcer prevention effectively.

Hicks et al (Hicks et al., 2019) The costs for DFU maintenance are very large and it also had a high profitability effect.

Cousart and Handley (Cousart \& Handley, 2017)

Rumana et al (Rumana et al., 2017)

Diabetic foot care in primary care was very effective and proved to be beneficial for preventing and healing process foot problems in diabetes mellitus patients. Facebook has proven to be effective to provide correct information regarding diabetic foot care by seeing the positive likes and comments.

Fan et al (Fan, Sidani, CooperBrathwaite, \& Metcalfe, 2013) The self-foot-care education interventions were acceptable, feasible and had good effects for treating the skin of the feet and toenails.

Stolt et al (Stolt et al., 2013)

Foot care in diabetes mellitus patients performed by home nurses must also have its associated scientific information updated. This should be done to obtain better results, especially in foot care.

Vatankhah et al (Vatankhah et al., Health education with a simple face-to-face method was an effective and 2009) implemented method to increase the knowledge regarding foot care.

effort planned to exert an influence on others. The output is to do what has been given in the process element. In general, the results expected in health education are health behaviors or behaviors undertaken to maintain and improve conductive health in the target(Notoatmodjo, 2012).

Besides having 3 important elements in health education, it should be known that the methods used in health education also need to be considered. There are 2 ways of giving health education; face-to-face in person or by using a certain media type. Media in health education can influence the success of the material that is delivered. The educational media that can be used includes electronic media (radio, tv, internet, telephone, cellphones, social media, etc.), print media (leaflets, posters, booklets, newspapers, magazines, etc.) and other media (letters). The determination of health education media is adjusted according to the number of targets, the geographical conditions, the characteristics of the participants and their supporting resources(Nursalam \& Efendi, 2008).

Health education is the starting point that can be initiated by health workers to have a good influence. One of the examples is providing health education to diabetes mellitus patients regarding proper foot care behavior.

Health Education through Electronic Media

Electronic media is one of the media types that can be 
used to provide health education. Electronic media is an assembled device that has a machine to support its operations. The development of an increasingly modern era affects the sophistication level of electronic media. Electronic media circulating in the community includes television, radio, cellphones etc. Within the development era, mobile phones have become one of the electronic media items owned by nearly everyone. Cellphones are now the main tool for people to find out the latest information, because each individual sees and holds cellphones almost every hour. Electronic media can establish two-way communication, not only by receiving but also by responding. In addition, electronic media can receive responses from an unlimited amount of sources and it can be used to exchange information (Garcia, 2011).

These changes and developments can be utilized in the health sector. The health teams are also required to think forward by using mobile electronic media for providing health education. One of the examples of health education is proper foot care behavior education for diabetic foot ulcer prevention. An example of a type of electronic media that can be used and that has been extensively studied is the use of social media and information delivery via SMS. These media types can have a positive effect on improving foot care behavior in diabetes mellitus patients.

\section{Health Education through Direct method/Face-to- Face}

The direct method of health education or the face-toface method is one of the most commonly used media. This media has various advantages and disadvantages. The advantage of the face-to-face media is that the health information providers can meet and provide direct feedback in person. However, the weakness of this media is the time and number of targets. In using this method, the counseling needs to be done at certain times and planned in advance. The targets must also spare a sufficient amount of time to attend the counseling. In addition, the amount of targets will be limited due to the small capacity of the counseling space (Musfiqon, 2012).

Health education using the face-to-face method requires the targets to pay full attention during the counseling. Despite many weaknesses of this media form, it is still an option for providing health education. Some of the studies stated that this method had good results, such as increasing the adherence to foot care behavior in diabetes mellitus patients for the prevention of gangrene and even amputation.

\section{Health Education in accordance with Cultures}

Culture is a form of habit by humans as members of a particular community containing knowledge, beliefs, art, morals, law, habits and other complex skills. The first time that nursing emerged in health context, it discussed the culture associated with nursing. There is a theory in nursing that is focused on learning about culture, referred to as the theory of Transcultural Nursing, namely Leininger's theory. The theory stated that the nursing practice as a whole needs to pay attention to the culture adopted and that it needs to provide information tailored to the content that is according to the culture as health workers (Aini, 2018).

Numerous research studies have also been done by developing the theories of Leinenger. Health education, especially on foot care behavior is also connected, with theory. This study found that health education conducted by paying attention to the cultural contexts adopted can increase the willingness of the patient and trust in the information conveyed. Therefore, giving health education in accordance with the local cultures can be a good influence on the diabetes mellitus patients when it comes to performing foot care behavior.

The behavior of diabetic foot care performed by diabetes mellitus patients is indispensable. Diabetic foot care behavior can prevent foot problems in diabetes mellitus patients. Foot problems in diabetes mellitus patients are the most common complications. The complications of diabetic feet can result in amputation, which can affect various aspects of the patient's life. Therefore, diabetes mellitus patients need to understand and implement foot care behavior. Nurses can help in foot care behavior education and they can assist in the development of techniques in terms of providing health education effectively to diabetes mellitus patients.

\section{CONCLUSION}

Foot care behavior is required to prevent diabetic foot complications. Foot care behavior has a positive impact if it is done properly. Health education regarding foot care behavior is also needed. Performing education and media selection is an aspect which needs to be taken into consideration. Examples of the media that can be selected and studied are SMS, social media and the face to face method. Health education using the right media will result in the improvement of foot care behavior in diabetes mellitus patients. Thus, it can also prevent the occurrence of diabetic foot complications leading to amputation. The limitation of this systematic review was that it only found 16 supporting literature items. Thus it could not explain all of the influential factors of self foot care and it could only explain the most important factor and related aspects.

\section{REFERENCES}

Adarmouch, L., Elyacoubi, A., Dahmash, L., El Ansari, N., Sebbani, M., \& Amine, M. (2017). Short-term effectiveness of a culturally tailored educational intervention on foot self-care among type 2 diabetes patients in Morocco. Journal of Clinical and Translational Endocrinology, 7, 54-59. https://doi.org/10.1016/j.jcte.2017.01.002 
Aini, N. (2018). Teori Model Keperawatan. Malang: UMM Press.

Al Sayah, F., Soprovich, A., Qiu, W., Edwards, A. L., \& Johnson, J. A. (2015). Diabetic Foot Disease, SelfCare and Clinical Monitoring in Adults with Type 2 Diabetes: The Alberta's Caring for Diabetes (ABCD) Cohort Study. Canadian Journal of Diabetes, 39(3), S120-S126. https://doi.org/10.1016/j.jcjd.2015.05.006

Cousart, T. H., \& Handley, M. (2017). Implementing Diabetic Foot Care in the Primary Care Setting. Journal for Nurse Practitioners, 13(3), e129e132. https://doi.org/10.1016/j.nurpra.2016.11.009

D’Souza, M. S., Ruppert, S. D., Parahoo, K., Karkada, S. N., Amirtharaj, A., Jacob, D., ... Al Salmi, N. M. D. (2016). Foot care behaviors among adults with type 2 diabetes. Primary Care Diabetes, 10(6), 442-451. https://doi.org/10.1016/j.pcd.2016.04.002

Fan, L., Sidani, S., Cooper-Brathwaite, A., \& Metcalfe, K. (2013). Feasibility, Acceptability and Effects of a Foot Self-Care Educational Intervention on Minor Foot Problems in Adult Patients with Diabetes at Low Risk for Foot Ulceration: A Pilot Study. Canadian Journal of Diabetes, 37(3), 195201.

https://doi.org/10.1016/j.jcjd.2013.03.020

Garcia, I. (2011). Social Media Integration Theory Model. Spanish: Human Media.

Hicks, C. W., Canner, J. K., Karagozlu, H., Mathioudakis, N., Sherman, R. L., Black, J. H., \& Abularrage, C. J. (2019). Quantifying the costs and profitability of care for diabetic foot ulcers treated in a multidisciplinary setting. Journal of Vascular Surgery, 1-8. https://doi.org/10.1016/j.jvs.2018.10.097

Indrayana, S., Guo, S. E., Lin, C. L., \& Fang, S. Y. (2019). Illness Perception as a Predictor of Foot Care Behavior Among People With Type 2 Diabetes Mellitus in Indonesia. Journal of Transcultural Nursing, 30(1), 17-25. https://doi.org/10.1177/1043659618772347

Li, R., Yuan, L., Guo, X. H., Lou, Q. Q., Zhao, F., Shen, L., ... Sun, Z. L. (2014). Ethe current status of foot self-care knowledge, behaviours, and analysis of influencing factors in patients with type 2 diabetes mellitus in China. International Journal of Nursing Sciences, 1(3), 266-271. https://doi.org/10.1016/j.ijnss.2014.05.023

Moradi, A., Alavi, S. M., Salimi, M., Nouhjah, S., \& Shahvali, E. A. (2019). The effect of short message service (SMS) on knowledge and preventive behaviors of diabetic foot ulcer in patients with diabetes type 2. Diabetes and Metabolic Syndrome: Clinical Research and
Reviews, 13(2), 1255-1260. https://doi.org/10.1016/j.dsx.2019.01.051

Musfiqon. (2012). Pengembangan Media dan Sumber Pembelajaran. Jakarta: PT. Prestasi Pustakarya.

Navarro-Flores, E., Morales-Asencio, J. M., CerveraMarín, J. A., Labajos-Manzanares, M. T., \& GijonNogueron, G. (2015). Development, validation and psychometric analysis of the diabetic foot self-care questionnaire of the University of Malaga, Spain (DFSQ-UMA). Journal of Tissue Viability, 24(1), 24-34. https://doi.org/10.1016/j.jtv.2014.11.001

Notoatmodjo, S. (2012). Promosi Kesehatan dan Perilaku Kesehatan. Jakarta: Rineka Cipta.

Nursalam, \& Efendi, F. (2008). Pendidikan Dalam Keperawatan. Jakarta: Salemba Medika.

Rumana, N., Abedin, T., Al Mamun, M., Turin, T. C., Shommu, N., Lasker, M. A. A., \& Ahmed, S. W. (2017). Social Media as a Platform for Information About Diabetes Foot Care: A Study of Facebook Groups. Canadian Journal of Diabetes, 41(1), 97-101. https://doi.org/10.1016/j.jcjd.2016.08.217

Sharoni, S. K. A., Abdul Rahman, H., Minhat, H. S., Shariff Ghazali, S., \& Azman Ong, M. H. (2017). A self-efficacy education programme on foot selfcare behaviour among older patients with diabetes in a public long-term care institution, Malaysia: A Quasi-experimental Pilot Study. BMJ Open, $\quad 7(6), \quad 1-11$. https://doi.org/10.1136/bmjopen-2016014393

Stolt, M., Suhonen, R., Puukka, P., Viitanen, M., Voutilainen, P., \& Leino-Kilpi, H. (2013). Nurses' foot care activities in home health care. Geriatric Nursing, 34(6), 491-497. https://doi.org/10.1016/j.gerinurse.2013.08.0 03

Vatankhah, N., Khamseh, M. E., Jahangiri Noudeh, Y., Aghili, R., Baradaran, H. R., \& Safai Haeri, N. (2009). The effectiveness of foot care education on people with type 2 diabetes in Tehran, Iran. Primary Care Diabetes, 3(2), 73-77. https://doi.org/10.1016/j.pcd.2009.05.003

Vedhara, K., Dawe, K., Wetherell, M. A., Miles, J. N. V., Cullum, N., Dayan, C., ... Campbell, R. (2014). Illness beliefs predict self-care behaviours in patients with diabetic foot ulcers: A prospective study. Diabetes Research and Clinical Practice, 106(1),

67-72. https://doi.org/10.1016/j.diabres.2014.07.018 Wendling, S., \& Beadle, V. (2015). Journal of Clinical \& Translational Endocrinology The relationship between self-effi cacy and diabetic foot self-care. 2 , https://doi.org/10.1016/j.jcte.2015.01.001 